\title{
4 - Notificações espontâneas de incidentes
}

\author{
Celsa Raquel Villaverde Melgarejo \\ Patricia de Carvalho Mastroianni \\ Fabiana Rossi Varallo
}

\section{SciELO Books / SciELO Livros / SciELO Libros}

MELGAREJO, C. R. V., MASTROIANNI, P. C., and VARALLO, F. R.

Notifica ções espontâneas de incidentes. In: Promoção da cultura de

notificação de incidentes em saúde [online]. São Paulo: Editora UNESP, 2019, pp. 29-32. ISBN: 978-85-9546-337-0.

https://doi.org/10.7476/9788595463370.0006.

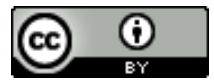

All the contents of this work, except where otherwise noted, is licensed under a $\underline{\text { Creative Commons Attribution } 4.0 \text { International license. }}$

Todo o conteúdo deste trabalho, exceto quando houver ressalva, é publicado sob a licença Creative Commons Atribição 4.0.

Todo el contenido de esta obra, excepto donde se indique lo contrario, está bajo licencia de la licencia Creative Commons Reconocimento 4.0. 


\section{4 \\ NOTIFICAÇÕES ESPONTÂNEAS \\ DE INCIDENTES}

A notificação espontânea de incidentes é o método mais comum e amplamente utilizado em diversas regiões do mundo. Consiste no relato voluntário de problemas relacionados ao uso de tecnologias e produtos, e falhas nos processos de cuidado (Leape, 2002; Brasil, 2013a). Portanto, o ato de notificar torna-se um importante instrumento para a melhoria da qualidade no sistema de saúde.

Por meio da notificação pode-se detectar possíveis erros, além de analisar eventos e circunstâncias de riscos, e esses eventos podem ser direcionados para o aprendizado, contribuindo para a segurança do paciente. As notificações espontâneas servem como um sinal de alerta sobre a necessidade de investigação clínica e para ajustar o sistema de atenção à saúde de modo a minimizar falhas durante a assistência (Herdeiro et al., 2012; Mota Gomes, 2001).

Uma das vantagens da notificação, além do baixo custo e da facilidade (Desai et al., 2011; Pal et al., 2013), está no fato de que qualquer pessoa pode realizá-la, de profissionais da saúde a pacientes e cuidadores até cidadãos em geral, pois ela tem como característica principal a confidencialidade. As notificações não necessitam de identificação e, portanto, não serão analisadas de maneira punitiva com relação a quem está envolvido no incidente (Leape, 2002), além 
de ser um dos objetivos primordiais para o aprendizado por meio de possíveis erros (OMS, 2011).

Entretanto, devido ao seu caráter de espontaneidade, o método possui várias limitações e desvantagens, resultando em índices elevados de subnotificações, pois o relato é dependente da iniciativa e da motivação de quem o realiza e, frequentemente, está relacionado à culpa de estar envolvido em um incidente; ao medo de punições; à falta de tempo; insegurança ao notificar; indiferença com a situação; complacência e ao sentimento de vergonha, aliados à falta de conhecimento sobre conceitos e processos de notificação; dificuldade de acesso ao formulário de notificação ou, ainda, à formulários mal elaborados, falta de clareza nos itens que devem ser preenchidos ou a quem deve ser encaminhado e quem o analisa (Capucho; Arnas; Cassiani, 2013; Duarte et al., 2015; Varallo et al., 2014).

Ainda como desvantagem, tem-se os relatos inconclusivos e incompletos, isto é, de má qualidade, que tornam a notificação espontânea um instrumento de difícil avaliação do risco (Johansson; Hägg; Wallerstedt, 2011; Mota Gomes, 2001).

Traçando um paralelo do processo de notificação com a figura de um iceberg (Figura 1), a subnotificação é representada pela parte submersa, ou seja, os casos omissos. A ponta do iceberg, "o que podemos ver", são os incidentes notificados, apesar de haver muitos incidentes ou circunstâncias de risco que não são notificados por motivos supracitados.

Outro ponto a ser abordado sobre as notificações na correlação com a figura do iceberg, precisamente a parte submersa, é o fator da qualidade do relato e a relevância das informações descritas nas fichas. No processo de avaliação das notificações, em sua maioria, há o apontamento do incidente apenas como descrição dos fatos, isto é, as causas do incidente, mas os fatores contribuintes não são discriminados nos formulários de notificações. Isso dificulta o processo de avaliação de cada caso, pois desconhecendo a série de causas, não é possível evidenciar o que está por trás do incidente, além de se tratar de um aspecto mais crítico é difícil de ser mensurado, sobretudo se 
não registrado (Santiago; Turrini, 2015). O registro incompleto impacta diretamente a segurança do sistema institucional.

A cultura de notificação faz parte da cultura de segurança, que é definida como o produto de valores e padrões comportamentais, individuais ou de equipe, vinculados ao tipo de gestão organizacional de uma instituição. Uma vez instalada a cultura de segurança no ambiente de trabalho, a instituição passa a ser vista como um órgão bem-estruturado, com comunicação efetiva, e gera confiança entre os indivíduos que ali desenvolvem suas atividades. Portanto, a avaliação da cultura de segurança por meio da cultura de notificação, permite reconhecer a situação da organização quanto à instituição, além de averiguar e mensurar o impacto das intervenções realizadas para a melhoria de processos (Reis; Laguardia; Martins, 2012; Santiago; Turrini, 2015).

Figura 1 - Esquema ilustrativo das subnotificações e descrição dos fatores causais.

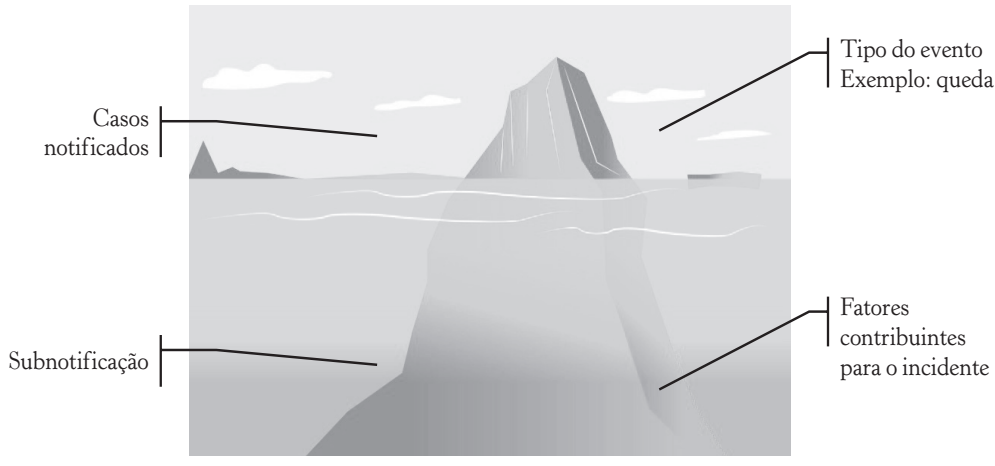

Fonte: Imagem modificada do banco de dados da Pixabay. Disponível em: $<$ https://pixabay. com/es/iceberg-el-agua-azul-oc\%C3\%A9ano-hielo-1421411/>.

O profissional da saúde participa do sistema do gerenciamento de riscos no momento que notifica, tendo em vista que, de fato, está colaborando com o sistema e a instituição, contudo a não devolução da ficha ao notificador pode indicar que houve falha na comunicação no processo de notificação produzindo descontentamento e desmotivação pelo não reconhecimento da colaboração prestada (Cristina et al., 2014; Paiva; Paiva; Berti, 2010; Paula et al., 2017). 
Além disso, a subnotificação pode estar atrelada ao equívoco de que somente enfermeiros podem notificar. Estudos nacionais apontam que o profissional da enfermagem é o principal notificador, além de ser considerado o responsável por essa ação (Capucho; Arnas; Cassiani, 2013; Figueiredo; Innocenzo, 2017). O fato de os enfermeiros estarem em contato direto e contínuo com o paciente, no que se refere à tempo, serem em maior número, comparados a outras categorias profissionais e, pelo fato de, muitas vezes, se tornarem responsáveis por uma equipe de técnicos e auxiliares, faz da categoria enfermagem um modelo de notificador.

No entanto, qualquer profissional da saúde pode realizar as notificações de incidentes. A notificação deve deixar de ser centrada no enfermeiro e faz-se necessária a promoção de orientação, conhecimento e estímulo as outras categorias para que haja participação efetiva de todos os profissionais no que se refere ao ato de notificar, pois a notificação de incidentes permite aos profissionais de saúde compartilhar responsabilidades e promover estímulos em busca da qualidade na assistência à saúde, para que não haja ocorrência repetida de erros e para a prevenção destes, futuramente. Portanto, a prática de registros, como conduta diária, faz do profissional um instrumento valioso, uma vez que propicia auxílio à gestão na assistência favorecendo a qualidade na prestação de serviços relacionados à saúde (Figueiredo; Innocenzo, 2017; Oliva et al., 2014).

A notificação proporciona o compartilhamento de responsabilidades e estimula ações corretivas, tendo em vista a ausência de reincidências de atos falhos e inseguros por parte do profissionais da saúde. Além disso permite revelar inadequações estruturais, ambientais, de recursos humanos, dentre outras fragilidades na instituição. Assim, a notificação é o ponto de partida na promoção de melhorias, como criação de grupos de cuidados, protocolos e incentivo à aprendizagem (Comissão Europeia, 2014; Cristina et al., 2014; Mira et al., 2013; Mitchell et al., 2016). 